\title{
Atrioventricular Dissociation with Intact Retrograde Conduction
}

\author{
EVAN FLETCHER AND PATRICIA MORTON \\ From the Cardio-Vascular Unit, Belfast City Hospital
}

\begin{abstract}
When orthograde atrioventricular conduction is completely blocked, the atrial rhythm may be disturbed by retrograde conduction of the idioventricular impulses. The underlying mechanisms in such cases are of physiological interest, as they permit comparison with experimental findings in isolated muscle strips and thereby lead to a better understanding of impulse formation and conduction disturbances in the human heart. Critical analysis of cardiograms of these cases may also have clinical importance, as it may help in the localization of myocardial lesions. Before the presentation of tracings it may be useful to review some of the relevant experimental and clinical data previously reported, upon which an understanding of the nature of the disturbance of rhythm depends.
\end{abstract}

Bidirectional conduction is a normal function of the atrioventricular connecting tissues, and may occur when a ventricular ectopic focus interferes with a dominant sinus rhythm (Kistin and Landowne, 1951). Usually, however, ectopic ventricular impulses are normally blocked at the atrioventricular node and fail to reach the atria. When conditions are reversed and orthograde sinus impulses are blocked, retrograde impulses from the ventricles being conducted to the atria, there is a defect of conduction in the heart due to some change in the conducting tissues. This paper is concerned with the nature of this change. Unidirectional block of impulse conduction can be produced experimentally in isolated muscle strips by mechanical or chemical damage (Ashman and Hafkesbring, 1929; Schmitt and Erlanger, 1928), and it is the basic defect of conduction in the pararrhythmia, interference dissociation (Mobitz, 1923; Scherf and Schott, 1953), and of return extrasystoles in the human heart (Scherf, 1941; Decherd and Ruskin, 1943; Fletcher and Stevenson, 1955). That nor-

Received August 2, 1967. mal orthograde conduction should be selectively blocked, retrograde conduction remaining intact and even occurring within a normal time period, seemed difficult to accept, and various alternative explanations were given for records similar to those shown in this paper. Cohn and Fraser (1914) first reported an instance of this disturbance of rhythm in a patient with syphilitic heart disease. They attributed the premature atrial activation to mechanical stimulation of the atria by the contracting ventricular mass. A similar mechanical theory was postulated by Barker (1926) who believed that the contracting ventricles stimulated an area of tissue immediately above the block and thereby activated the atria. Although these mechanical theories may now be discarded as they failed to explain constant features of future cases, especially the relation of premature activation of the atria to the dominant atrial cycle lengths, nevertheless mechanical ventricular systole may affect the atrial rhythm by a positive chronotropic effect, causing accelerated stimulus formation in the sinus node (Rosenbaum and Lepeschkin, 1955). This mechanism is entirely distinct from retrograde conduction, from which it has to be differentiated. Retrograde conduction most commonly takes place when ventricular systole occurs in late atrial diastole. Daniélopolu and Danulesco (1922) believed that this depended upon the refractory period of the atrial muscle. These authors were first to suggest retrograde conduction in orthograde atrioventricular block, but they postulated that aberrant pathways conveyed the impulse to the atria. However, in an extensive review of the subject by Winternitz and Langendorf (1944), it appears that it is the state of the area of depression in the conducting tissues that determines retrograde conduction. Moreover, the cases of these authors and of Wolferth and McMillan (1929) support the view that retrograde conduction takes place along the normal 


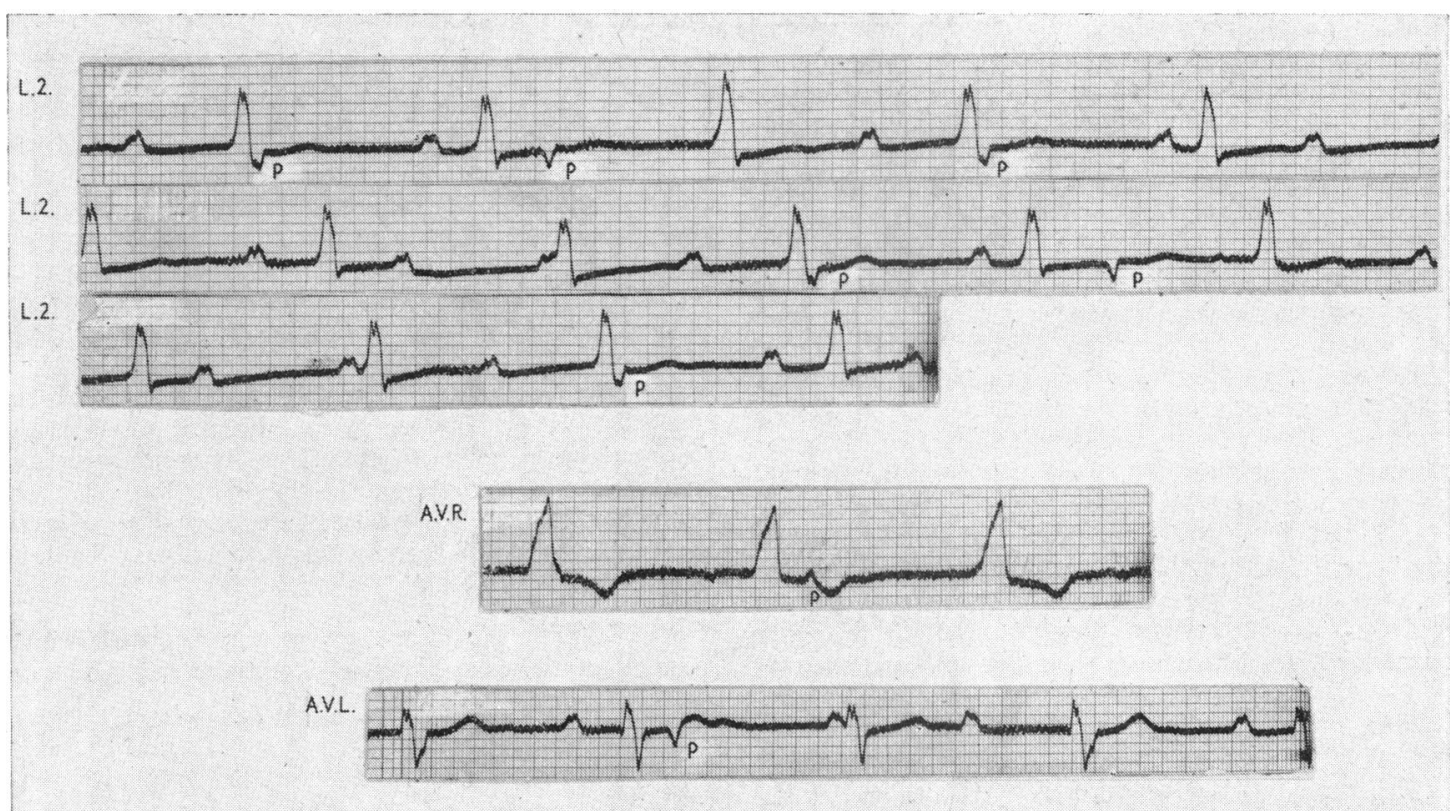

FIG. 1.- Complete orthograde atrioventricular block with intact retrograde conduction ( $p$ waves). Time marker, $0.02 \mathrm{sec}$. Lead II is continuous. The shortest $P-R$ interval followed by retrograde conduction is $0.2 \mathrm{sec}$, related to the penultimate ventricular complex of the middle strip of lead II. The ventricular rate is 60 a minute and the atrial rate 100 a minute.

atrioventricular pathways, and not via abnormal pathways as in the accelerated atrioventricular conduction of the pre-excitation syndrome. The cases described below fulfil the criteria laid down by Winternitz and Langendorf (1944) for the cardiographic diagnosis of retrograde conduction in atrioventricular block. They offer the opportunity to study the mechanisms involved, and to compare them with previously reported cases.

\section{CASE Reports}

Case 1 (Fig. 1). A woman of 70 years who had coronary artery disease was admitted to hospital with a history of Adams-Stokes attacks. No digitalis had been given. Serial cardiograms over a period of seven days confirmed varying degrees of atrioventricular block. When the block appeared complete, retrograde conduction was noted. The tracing is a cutting from a record taken 15 minutes after a syncopal attack to illustrate this phenomenon. Lead II is continuous, and a detailed analysis of its 24 atrial cycle lengths with regard to recovery periods for retrograde conduction is given in Table $\mathrm{I}$. Orthograde conduction appears to be completely blocked. The ventricular rhythm is regular, rate $60 / \mathrm{min}$. The dominant atrial rhythm is also regular, rate $100 / \mathrm{min}$. The atrial rhythm is disturbed by the occurrence of premature $P$ waves ( $p$ waves) which are opposite in polarity to the sinus $\mathbf{P}$ waves, and are different in shape from them. (Fig. 1, inverted $\mathrm{p}$ waves follow ventricular complexes Nos. $1,2,4,9,10$, and 14, lead II.) These $p$ waves represent intact retrograde
TABLE I

ANALYSIS OF THE 24 ATRIAL CYCLE LENGTHS OF FIG. 1 (LEAD II), WITH REGARD TO RECOVERY PERIODS FOR RETROGRADE CONDUCTION

\begin{tabular}{|c|c|c|c|c|c|}
\hline $\begin{array}{l}\text { Atrial } \\
\text { cycle } \\
\text { No. }\end{array}$ & $\mathbf{P - R}{ }_{(\text {sec. })}^{\mathbf{P}-\mathbf{p}}$ & R-p & $\begin{array}{c}\text { p-P } \\
\text { (sec.) }\end{array}$ & $\mathbf{P - R} \begin{array}{c}\mathbf{P}-\mathbf{P} \\
\text { (sec.) }\end{array}$ & R-P \\
\hline 1 & 0.56 & 0.12 & - & - & \\
\hline $\begin{array}{l}2 \\
3\end{array}$ & $0 \overline{52}$ & 0.20 & 0.7 & - & \\
\hline $\begin{array}{l}4 \\
5\end{array}$ & 二 & & $\stackrel{0.69}{-}$ & $0.03^{0.6}$ & 0.57 \\
\hline $\begin{array}{l}6 \\
7 \\
8\end{array}$ & $\begin{array}{r}0.4^{0.5} \\
=\end{array}$ & $0 \cdot 1$ & $\begin{array}{l}- \\
0.72\end{array}$ & $\overline{0.6}$ & \\
\hline $\begin{array}{r}9 \\
10 \\
11\end{array}$ & 二 & & 三 & $\begin{array}{r}0.18 \\
0.6 \\
0.6 \\
0.6\end{array}$ & 0.42 \\
\hline $\begin{array}{l}12 \\
13\end{array}$ & 二 & & 二 & $\begin{array}{r}0.28 \\
0.6 \\
0.6\end{array}$ & 0.32 \\
\hline 14 & $0.43^{0.53}$ & 0.1 & - & - & \\
\hline $\begin{array}{l}15 \\
16\end{array}$ & $0.2^{0.57}$ & $0 \cdot 37$ & $\stackrel{0.67}{-}$ & - & \\
\hline $\begin{array}{l}17 \\
18 \\
19\end{array}$ & 二 & & $\begin{array}{c}0.62 ? \\
=\end{array}$ & $\begin{array}{l}0 \overline{6} ? \\
0.6\end{array}$ & \\
\hline $\begin{array}{l}20 \\
21 \\
22\end{array}$ & $\frac{\overline{7}}{0.57}$ & 000 & 二 & $\begin{array}{r}0.32 \\
0.6 \\
0.6 \\
\end{array}$ & 0.28 \\
\hline $\begin{array}{l}23 \\
24\end{array}$ & $=$ & 009 & $\underline{0.65}$ & $0 \cdot 26^{0 \cdot \overline{6}}$ & 0.34 \\
\hline
\end{tabular}


ventriculo-atrial conduction. Retrograde conduction is also seen following the second ventricular complex in lead AVR, and the second and fourth ventricular complexes in lead AVL. In lead AVR the retrograde $p$ wave is positive, but opposite in polarity to the sinus $P$ waves. Ventriculophasic sinus arrhythmia (Erlanger and Blackman, 1910; Hecht, 1914; Winternitz and Lagendorf, 1944) can be excluded, as the atrial cycle lengths are the same length $(0.6 \mathrm{sec}$.) whether or not they contain a ventricular complex, provided retrograde conduction has not occurred (Table I, P-P intervals No. 5, 8-13, 18-21, and 24). When atrial and ventricular activation are closely related in time, superposition beats occur, i.e. the algebraic summation of electrograms of various portions of the heart stimulated simultaneously or nearly so (Fig. 1, ventricular complexes No. 3 and 8). When superposition does not occur the ventricular complexes are identical in shape, confirming that the ventricles are activated by a single focus. Table I confirms that the atrial cycle lengths terminated by retrograde conduction, i.e. the P-p intervals are invariably shorter than those of the dominant sinus rhythm, i.e. the P-P intervals, whereas the atrial cycle lengths initiated by retrograde conduction, i.e. the p-P intervals, are invariably longer than them. In addition, the sum of $P-p$ and $p-P$ intervals related in time is equal to, or just greater than, the sum of two P-P intervals. Therefore, though retrograde conduction disturbs the atrial rhythm by causing premature atrial activation, the excitation wave fails to reach the sinus node before the next normal sinus impulse is discharged. Thus, the basic sinus rhythm is not disturbed by retrograde conduction and is resumed at the expected time following it, i.e. the p-P intervals are compensatory. The shortest $\mathbf{P}-\mathbf{R}$ interval associated with retrograde conduction is $0.2 \mathrm{sec}$. (Table $\mathrm{I}$, atrial cycle No. 16), and the longest P-R interval not associated with retrograde conduction is $0.32 \mathrm{sec}$. (Table $I$, atrial cycle No. 19).

Case 2 (Fig. 2): The tracing was recorded from a woman of 62 years, who had coronary artery disease,

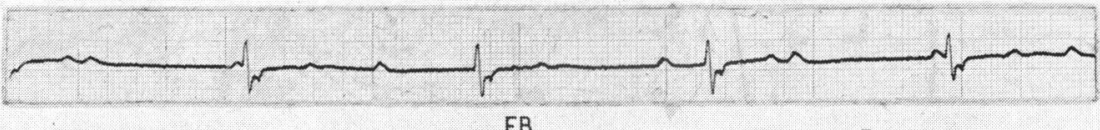

FB
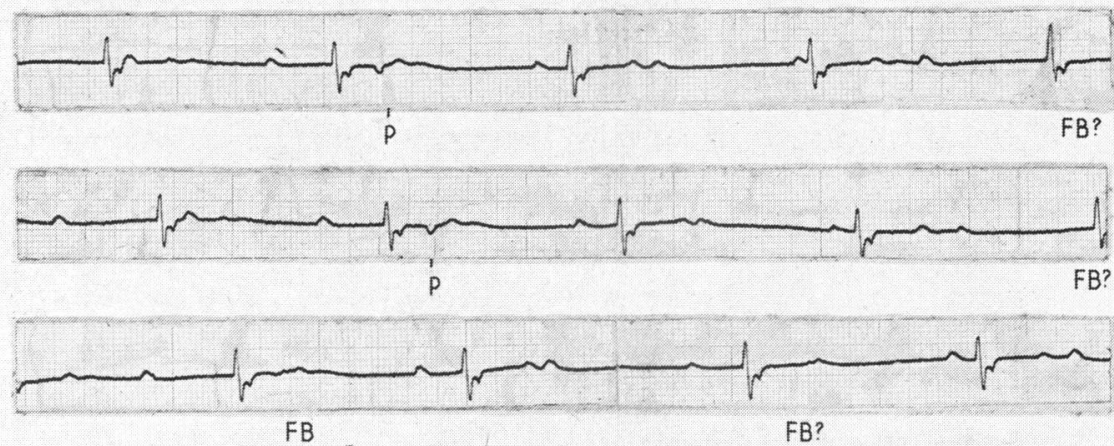

FB?

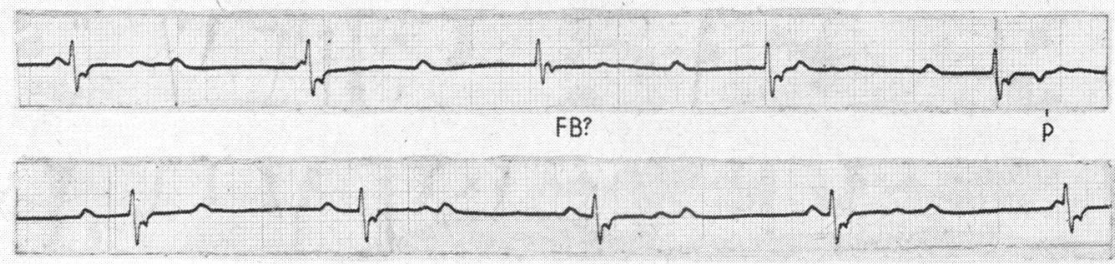

FIG. 2.-Complete orthograde atrioventricular block with intact retrograde conduction (p waves). Time marker, $0.04 \mathrm{sec}$. The tracing is a continuous strip of lead II. Simultaneous atrial activation by sinus and retrograde impulses explains the absence of manifest $P$ waves, fused atrial beats (FB). The shortest P-R intervals preceding retrograde conduction are $0.40 \mathrm{sec}$. related to the penultimate ventricular complex in fourth strip (FB ?), and 0.45 sec. related to the seventh ventricular complex in second strip (p). 
and who had a history of recurrent Adams-Stokes attacks over a period of three years. No digitalis had been given at any time. Orthograde conduction appears to be completely blocked. Table II shows an analysis of the time relationship of the 50 atrial cycle lengths of the tracing. The idioventricular rhythm is regular, rate $37 / \mathrm{min}$. The shortest atrial cycle lengths, P-p, No. 10, 19, and 41 (Table II), are terminated by retrograde conduction ( $\mathrm{p}$ waves in Fig. 2). The related P-R intervals measure from 0.45 to $0.48 \mathrm{sec}$. (Table II, No. 10 and 41 , respectively), i.e. retrograde conduction has occurred relatively late in atrial diastole. However, it should be noted that in Table II, No. 17 and 39, the $P-R$ intervals measure $0.72 \mathrm{sec}$. and $0.64 \mathrm{sec}$., respectively, and yet do not appear to be followed by retrograde conduction (Fig. 2, QRS complexes, No. 11 and 23). The basic sinus rhythm is irregular, as indicated by the varying P-P intervals in Table II. It is not possible, therefore, to be certain whether or not the p-P intervals No. 11,20 , and 42 , which measure 0.96 to $1.08 \mathrm{sec}$., are compensatory, i.e. whether or not the sinus node is discharged by the retrograde impulse. Retrograde conduction is delayed from 0.26 sec. (Table II, R-p interval No. 41) to $0.29 \mathrm{sec}$. (Table II, R-p intervals, No. 10 and 19). Immediately following ventricular complexes No. $3,10,15,16,18$, and 22 , it appears likely that the atria are activated simultaneously or nearly so, by the sinus and retrograde impulses, i.e. fused atrial beats have occurred (FB in Fig. 2). This explanation is supported by their occurrence relatively later in atrial diastole.

\section{Discussion}

It is now generally believed that the fundamental mechanism involved in retrograde conduction of idioventricular impulses in orthograde atrioventricular block depends upon some change in the atrioventricular conducting tissues at the site of the block. Scherf and Schott (1953) favour the explanation of facilitation of conduction in the Purkinje system analogous to that known to occur in nervous tissue (Skramlik, 1920). They use the term in a wide sense, implying that a sinus impulse occurring near the time of an idioventricular impulse may enter the Purkinje system and produce a change at the site of the block which "facilitates" the passage of the retrograde impulse to the atria. However, such a mechanism would mean that retrograde conduction can only occur in late atrial diastole. While it may explain many instances of this phenomenon, it has been noted in Fig. 1 that retrograde conduction also occurred with a $P-R$ interval of $0.20 \mathrm{sec}$. This is the shortest P-R interval associated with retrograde conduction known to us (Kline, Conn, and Rosenbaum (1939) had claimed hitherto that the shortest $P-R$ interval was 0.32 sec.). It appears, however, that other mechanisms may also play a part. Adrian and Lucas (1912) have demonstrated a supernormal phase of recovery in muscle
TABLE II

ANALYSIS OF THE 50 ATRIAL CYCLE LENGTHS OF FIG. 2 (LEAD II) WITH REGARD TO THE RECOVERY PERIOD FOR RETROGRADE CONDUCTION

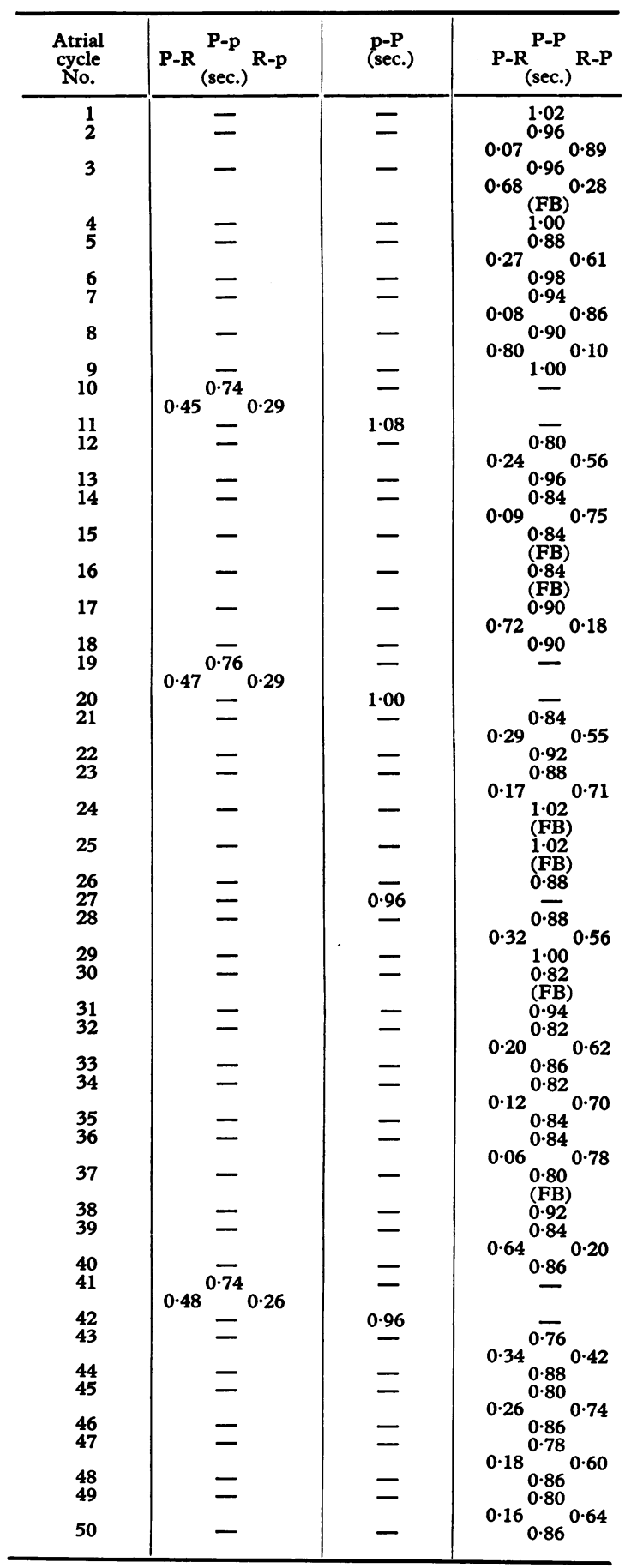


tissue, i.e. a temporary overswing of the recovery curve of the excitable phase after the transmission of an impulse, so that subthreshold stimuli occurring at this phase become superthreshold. In Fig. 1 there is a critical duration of P-R interval between 0.20 sec. and $0.32 \mathrm{sec}$. in which retrograde conduction may or may not occur. In Table I the P-R interval of P-p No. 16 measures 0.20 sec., whereas the P-R interval of P-P No. 19 measures 0.32 sec. Supernormal conduction may afford an explanation of this phenomenon. Several clinical cases of the supernormal phase of recovery have been described by Scherf and Schott (1953) and by Mack, Langendorf, and Katz (1947). In addition, the atrial rate seems to play a part in retrograde conduction. According to Winternitz and Langendorf (1944) it requires to be less than 120 a minute, and in the cases described the atrial rates were between 86 and 100 a minute. Since two separate foci activate the heart side by side in the presence of ventriculoatrial conduction, the slower ventricular focus being protected by orthograde atrioventricular block, and at times interfering with the atrial rhythm, the resulting dysrhythmia may be classified as a pararrhythmia, i.e. ventriculo-atrial interference dissociation (Winternitz and Langendorf, 1944). However, in the commoner type of interference dissociation between atria and ventricles the idioventricular pacemaker is situated in the atrioventricular node and is discharged by the conducted orthograde impulse, whereas in the rhythm under review the retrograde impulse may fail to reach the sinus node which dominates the atrial rhythm. Thus, retrograde conduction in atrioventricular block is analogous to the rarer type of interference dissociation, in which the idioventricular pacemaker is situated in the ventricles and not in the atrioventricular node. The limited pathological observations in some of these cases suggest that the lesion causing the block is in the main bundle of His near the bifurcation (Wolferth and McMillan, 1929; Lequime and Sanabria, 1937; Winternitz and Langendorf, 1944).

Most reported cases of intact retrograde conduction in atrioventricular block have coronary artery disease, as in our cases (Winternitz and Langendorf, 1944). It has not been described in congenital heart block. Digitalis plays no part in its occurrence and may abolish retrograde conduction as in the second case of Winternitz and Langendorf (1944). In our cases, retrograde conduction was only present when orthograde block appeared to be complete, and this concurs with the opinion expressed by Scherf and Schott (1953). The cardiographic diagnosis depends upon the presence of premature inverted $p$ waves in lead II. In lead I the retrograde $p$ waves may be positive, and differen- tiation from ventriculophasic sinus arrhythmia may be impossible.

\section{SUMMARY}

Retrograde conduction in complete orthograde atrioventricular block uses the normal conducting pathways. It represents ventriculo-atrial dissociation with interference. The underlying mechanism is discussed. Facilitation of the retrograde impulse accounts for its occurrence in late atrial diastole, but in some instances associated with a relatively short P-R interval supernormal recovery phase in the area of block may afford an explanation.

\section{REFERENCES}

Adrian, E. D., and Lucas, K. (1912). On the summation of propagated disturbances in nerve and muscle. $\mathcal{f}$. Physiol. (Lond.), 44, 68.

Ashman, R., and Hafkesbring, R. (1929). Unidirectional block in heart muscle. Amer. F. Physiol., 91, 65.

Barker, P. S. (1926). The occurrence of auricular beats due to stimulation of the auricles by the contracting ventricles during complete heart block. Amer. Heart $\mathcal{F}$., $1,349$.

Cohn, A. E., and Fraser, F. R. (1914). The occurrence of auricular contractions in a case of incomplete and complete heart block due to stimuli received from the contracting ventricles. Heart, 5,141 .

Daniélopolu, D., and Danulesco, V. (1922). Sur la conductibilité rétrograde et sur la phase réfractoire de l'oreillette. Arch. Mal. Coeur, 15, 365.

Decherd, G., and Ruskin, A. (1943). Studies of the properties of the A-V node: I. Reciprocal rhythm. II. Drug effects on the A-V function. Tex. Rep. Biol. Med., $1,299$.

Erlanger, J., and Blackman, J. R. (1910). Further studies on the physiology of heart block in mammals. Heart, $1,177$.

Fletcher, E., and Stevenson, M. (1955). Dissociation with interference, reciprocal rhythm and coronary sinus rhythm. Brit. Heart f., 17, 285.

Hecht, A. F. (1914). Das Morgagni-Adams-Stokes'sche Syndrom im Kindesalter und seine Behandlung. Wien. med. Wschr., 64, 177.

Kistin, A. D., and Landowne, M. (1951). Retrograde conduction from premature ventricular contractions, a common occurrence in the human heart. Circulation,
$\mathbf{3}, 738$.

Kline, E. M., Conn, J. W., and Rosenbaum, F. F. (1939). Variations in A-V and V-A conduction dependent on the time relations of auricular and ventricular systole: supernormal phase. Amer. Heart F., 17, 524.

Lequime, J., and Sanabria, T. (1937). Contribution à l'étude anatomo-clinique du bloc auriculo-ventriculaire complet permanent à rhythme ventriculaire lent. Arch. Mal. Coeur, 30, 670.

Mack, I., Langendorf, R., and Katz, L. N. (1947). The supernormal phase of recovery of conduction in the human heart. Amer. Heart $\mathcal{F}$., 34, 374.

Mobitz, W. (1923). Ueber die verschiedene Entstehungsweise extrasystolischer Arhythmien beim Menschen, ein Beitrag zur Frage der Interferenz mehrerer Rhythmen. Z. ges. exp. Med., 34, 490. 
Rosenbaum, M. B., and Lepeschkin, E. (1955). The effect of ventricular systole on auricular rhythm in auriculoventricular block. Circulation, 11, 240.

Scherf, D. (1941). An experimental study of reciprocating rhythm. Arch. intern. Med., 67, 372.

-, and Schott, A. (1953). Extrasystoles and Allied Arrhythmias. Heinemann, London.

Schmitt, F. O., and Erlanger, J. (1928). Directional differences in the conduction of the impulse through heart muscle and their possible relation to extrasystolic and fibrillatory contractions. Amer. F. Physiol., 87, 326.
Skramlik, E. von (1920). Die Bahnung der Erregung. Pflïgers Arch. ges. Physiol., 180, 30.

Winternitz, M., and Langendorf, R. (1944). Auriculoventricular block with ventriculo-auricular response. Amer. Heart f., 27, 301.

Wolferth, C. C., and McMillan, T. W. (1929). Observations on the mechanisms of relatively short intervals in ventriculoauricular and auriculoventricular sequential beats during high grade heart block. Amer. Heart f., 4, 521. 